\title{
Removal of Sunfix Blue SF-RL dye from aqueous solution using methyl methacrylate/ Na-Y-Zeolite composite
}

\author{
M.S. Ibrahem ${ }^{1}$, A.Z. El-Sonbati ${ }^{* 2}$, M.A. Diab ${ }^{2}$, T.Y. Al-Said ${ }^{1}$ \\ ${ }^{1}$ Environmantal Sciences Department, Faculty of Science, Damietta University, Damietta, Egypt. \\ ${ }^{2}$ Chemistry Department, Faculty of Science, Damietta University, Damietta, Egypt \\ Received: 19 March 2018 /Accepted: 25 March 2018 \\ * Corresponding author: elsonbatisch@yahoo.com
}

\begin{abstract}
The adsorption of Sunfix Blue SF-RL dye onto methyl methacrylate/ Na-Y-Zeolite (MMA/Na-Y$\mathrm{Z}$ ) composite was investigated in aqueous solution in a batch system with respect to contact time, $\mathrm{pH}$, adsorbent dosage and temperature. Physical characteristics of (MMA/Na-y-Z) composite such as Fourier transform infrared spectroscopy (FT-IR), X-ray diffraction (XRD) were obtained. Langmuir and Freundlich adsorption models were applied to describe the equilibrium isotherms and the isotherm constants were determined. The activation energy of adsorption was evaluated for the adsorption of Sunfix Blue SF-RL dye onto (MMA/Na-Y-Z) composite. The pseudo-first-order and pseudo-second-order kinetic models were used to describe the kinetic data. The dynamic data fitted the pseudo-second-order kinetic model for the adsorption of Sunfix Blue SF-RL dye. The activation energy (Ea), change of free energy $(\Delta \mathrm{G})$, enthalpy $(\Delta \mathrm{H})$ and entropy $(\Delta \mathrm{S})$ of adsorption were also evaluated for the adsorption of Sunfix Blue SF-RL dye onto (MMA/Na-Y-Z) composite. The thermodynamics of the adsorption indicated spontaneous and endothermic process for Sunfix Blue SF-RL dye. The results indicate that (MMA/Na-Y-Z) composite could be employed as low-cost material for the removal of dyes from industrial wastewater.
\end{abstract}

Keywords: Sunfix Blue SF-RL dye / Na-Y-Zeolite composite, adsorption efficiency, sorption kinetics, thermodynamic parameters.

\section{Introduction}

Water contamination caused by dye industries, including food, leather, textile, plastic, cosmetics, paper-making, printing and dye synthesis, has caused more and more attention, since most dyes are harmful to human being and environments [1]. Therefore, these industrial effluents must be treated before discharge. Currently, much attention has been paid to the removal of dyes from industrial wastewater [2]. Various treatment methods including physical, chemical and biological schemes have been developed to remove dyes from wastewater [2-4]. However, these methods mentioned above always show some disadvantages, such as the generation of large amounts of toxic and carcinogenic byproducts, intensive energy and high cost. Some of the applied techniques for the treatment of dye contaminated wastewaters are flocculation, coagulation, precipitation, adsorption, membrane filtration, electrochemical techniques, ozonation and fungal decolorization $[5,6]$. Among them, the adsorption-based procedure is widely utilized due to its high efficiency, capacity and ability for large scale dye removal application (with potential for 
adsorbent regeneration) [6-10]. The nontoxic, low cost and easy availability adsorbents are the best choice for wastewater treatment. Due to the unique properties of nanoparticles such as a high number of reactive atoms, high mechanical and thermal strength, large number of vacant reactive surface sites metallic or semi-metallic behavior and high surface area widely applied for removal of various toxic materials [11]. To our delight, adsorption is an economic, effective and easily operated process in dye removal [12]. Numerous adsorbents, such as zeolite, silica, wheat shells, orange peel, coir pith, almond shells, natural polymeric materials, etc. have been studied and applied [13].

The industrial wastewater usually contains a variety of organic compounds and toxic pulp mills and dyestuff manufacturing discharge highly colored wastewater which have provoked serious environmental concerns all over the world [14]. Several methods including adsorption [15], coagulation [16], membrane filtration [17] and advanced oxidation [18] have been employed to eliminate dyes from wastewaters. Among them, adsorption has been recognized as a promising technique due to its high efficiency, simplicity of design, ease of operation as well as the wide suitability for diverse types of dyes $[19,20]$. Because the dye effluent may cause damage to aquatic biota and human by mutagenic and carcinogenic effects, the removal of dye pollutants from wastewater is of great importance [21].

Adsorption is considered to be relatively superior to other techniques because of its low cost, simplicity of design, ease of operation, flexibility, high efficiency, availability and ability to separate wide range of chemical compounds [22, 23]. Currently, zeolite is the most common adsorbent $[24,25]$. Because zeolites are crystalline alluminosilicates with the structure based on tetrahedral $\mathrm{SiO}_{4}$ and $\mathrm{AlO}_{4}$ units, connected by shared oxygen atoms, and the isomorphous replacement of $\mathrm{Si}^{4+}$ by $\mathrm{Al}^{3+}$ produces a negative charge in the lattices. Which is compensated by alkali and alkaline-earth metal cations within the frame work. Thus, each mole of aluminum produces one equivalent of cation exchange capacity for the zeolite frame work. [26, 27]. Polymeric adsorbents are generally preferred due to their high efficiency, easy handling, availability of different adsorbents reusability and the cost effectiveness.

The aim of this study is to investigate the adsorption of hazardous Sunfix Blue SF-RL dye onto methyl methacrylate/ Na-Y-Zeolite
(MMA/Na-Y-Z) composite. Effects of different parameters such as initial adsorbate concentration, adsorbent dosage, contact time, solution $\mathrm{pH}$ and temperature were studied. The kinetic and thermodynamic parameters were also calculated to determine rate constants and adsorption mechanism. The experimental data were fitted into Langmuir and Freundlich equations to determine which isotherm gives the best correlation to experimental data.

\section{Experimental}

\section{Chemicals and reagents}

All chemicals used were of analytical reagent grade and distilled water was used for the preparation of all aqueous solutions, Methyl methacrylate (MMA) was Loba Analytical products. It was washed with caustic soda solution to remove the inhibitor, subsequently with distilled water and dried over calcium hydride. The monomer was vacuum-distilled, the first and last $20 \%$ being eliminated. Na-Y Zeolite and sodium bisulfite were Fluka Analytical products.

\section{Preparation of poly (methyl methacrylate) (PMMA).}

PMMA was prepared by free radical initiation of MMA monomer using $0.1 \mathrm{~g}$ of sodium bisulfite and $50 \mathrm{ml}$ distilled water in $250 \mathrm{ml}$ conical flask. The polymerization was carried out in a thermostate at $50^{\circ} \mathrm{C}$ for 24 hours. The formed PMMA was isolated by filtration, washed with distilled water followed by ethanol and dried in drying oven for four days at $50^{\circ} \mathrm{C}$ yield $95 \%$ of PMMA.

\section{Preparation of methyl methacrylate / $\mathrm{Na}-\mathrm{Y}$ - Zeolite (MMA/Na-Y-Zeolite) composite.}

MMA/ Na-Y-Zeolite composite was prepared through solution polymerization of MMA $(20 \mathrm{ml})$ monomer and Na-Y Zeolite (20g) using $0.3 \mathrm{~g}$ of Sodium bisulfite as initiator in $50 \mathrm{ml}$ distilled water. The polymerization was carried out at $50^{\circ} \mathrm{C}$ with continuous stirring for 24 hours and the product was isolated by filtration and washed with distilled water followed by ethanol then air dried. The product was grinded to fine particles. 


\section{Characterization of the sorbents}

In order to confirm the functionalization of the sorbent; methyl methacrylate / Na-Y-Zeolite resin was examined in dried $\mathrm{KBr}$ powder by recording the infrared spectra over the range of 4000-400 $\mathrm{cm}^{-1}$ using a Fourier transform infrared spectrophotometer (FTIR) (Jasco FT/IR-4100 spectrophotometer). The structure of the synthesized adsorbent was examined by X-ray diffraction measurement (XRD) is recorded on $\mathrm{X}$ ray diffract meter in the range of diffraction angle $2 \theta=5-80^{\circ}$. This analysis is carried out using $\mathrm{Cu}$ $\mathrm{K} \alpha 1$ radiation $(\lambda=1.540598 \AA)$.

\section{Determination of point of zero charge}

The point of zero charge (pHpzc) was determined by solid addition method. A series of $0.1 \mathrm{M} \mathrm{KNO}_{3}$ solution $(50 \mathrm{ml}$ each) were prepared and their $\mathrm{pH}$ values were adjusted in the range of 1.0 to 11.0 by addition of $0.1 \mathrm{M} \mathrm{HCl}$ and $0.1 \mathrm{M} \mathrm{NaOH}$. To each solution, $0.1 \mathrm{~g}$ of MMA/Zeolite composite was added and the suspensions were shaked manually and the solution was kept for a period of $48 \mathrm{~h}$ with intermittent manual shaking. The final $\mathrm{pH}$ of the solution was recorded and the difference between initial and final $\mathrm{pH}(\Delta \mathrm{pH})(\mathrm{Y}$-axis) was plotted against the initial $\mathrm{pH}$ (X-axis). The point of this curve yielded pHpzc [28].

\section{Preparation of solutions}

Distilled water was used for the preparation of all aqueous solutions. A stock solution $\left(1000 \mathrm{mgL}^{-1}\right)$ of Sunfix Blue SF-RL dye was prepared in distilled water. The desired concentrations were then obtained by dilution. $\mathrm{HCl}(0.01-0.1 \mathrm{~N})$ and $\mathrm{NaOH}(0.01-0.1 \mathrm{~N})$ were used to control the $\mathrm{pH}$ of the medium.

\section{Sorption experiments}

Batch adsorption studies were carried out by shaking $50 \mathrm{ml}$ conical flasks containing $0.25 \mathrm{~g}$ of MMA/ Na-Y-Zeolite composite and $25 \mathrm{~mL}$ of dye solutions of desired concentration with adjusted $\mathrm{pH}$ on an orbital shaker machine at $200 \mathrm{rpm}$ at $25^{\circ} \mathrm{C}$. The solution $\mathrm{pH}$ was adjusted with $0.1 \mathrm{~mol} \mathrm{~L}^{-1} \mathrm{HCl}$ and $0.1 \mathrm{~mol} \mathrm{~L}^{-1} \mathrm{NaOH}$ solutions. At the end of the adsorption period, the clear solution was separated by filtration. Then the concentration of the residual dye was determined spectrophotometrically by monitoring the absorbance at $613 \mathrm{~nm}$ for dye using UV-Vis spectrophotometer. Percentage of Dye removal (R) was calculated using eq. (1):

$\mathrm{R}=100\left(\mathrm{C}_{0}-\mathrm{C}_{\mathrm{t}}\right) / \mathrm{C}_{0}$

where $\mathrm{C}_{0}\left(\mathrm{mg} \mathrm{L}^{-1}\right)$ and $\mathrm{C}_{\mathrm{t}}\left(\mathrm{mg} \mathrm{L}^{-1}\right)$ are dye concentration initially at time $t$, respectively. For adsorption isotherms, dye solutions different concentrations $\left(20-100 \mathrm{mg} \mathrm{L}^{-1}\right)$ were agitated with known amounts of adsorbents until the equilibrium was achieved. Equilibrium adsorption capacity, $\mathrm{q}_{\mathrm{e}}$ ( $\mathrm{mg}$ dye per $\mathrm{g}$ adsorbent) was calculated from the following eq. (2):

$\mathrm{q}_{\mathrm{e}}=\mathrm{V}\left(\mathrm{C}_{0}-\mathrm{C}_{\mathrm{t}}\right) / \mathrm{W}$

where $\mathrm{C}_{\mathrm{t}}\left(\mathrm{mg} \mathrm{L}^{-1}\right)$ is the dye concentration at equilibrium, $\mathrm{V}(\mathrm{L})$ is the volume of solution and $\mathrm{W}(\mathrm{g})$ is the weight of adsorbent.

The procedures of kinetic experiments were identical with those of equilibrium tests. At predetermined moments, aqueous samples $(5 \mathrm{~mL})$ were taken from the solution, the liquid was separated from the adsorbent magnetically and concentration of dye in solution was determined spectrophotometrically at a wavelength of $613 \mathrm{~nm}$. The amount of dye adsorbed at time $\mathrm{t}, \mathrm{q}_{\mathrm{t}}$ (mg. $\mathrm{g}^{-1}$ ) was calculated by following eq. (3): $\mathrm{q}_{\mathrm{t}}=\mathrm{V}\left(\mathrm{C}_{0}-\mathrm{C}_{\mathrm{t}}\right) / \mathrm{m}$

where $\mathrm{C}_{0}\left(\mathrm{mg} \mathrm{L}^{-1}\right)$ is the initial dye concentration, $\mathrm{C}_{\mathrm{t}}\left(\mathrm{mg} \mathrm{L}^{-1}\right)$ the dye concentration at any time t, V (L) the volume of the solution and $\mathrm{m}(\mathrm{g})$ is the mass of the adsorbent.

In an adsorption study, it is necessary to fit the equilibrium adsorption data using different adsorption isotherm models and kinetic equations in order to analyze and design an adsorption process. Therefore, different theoretical models are applied to experimental data in order to find a model which adequately predicts kinetic and isotherm data. The validity of the models was evaluated by the coefficient of determination $\left(\mathrm{r}^{2}\right)$ [29].

The regeneration efficiency (RE, \%) was calculated according to the following equation:

$\mathrm{RE} \%=\frac{\text { Amount of sorbed metal }(\mathrm{mg}) \text { at run }(\mathrm{n}+1)}{\text { Amount of sorbed metal }(\mathrm{mg}) \text { at run }(\mathrm{n})} \times 100$

\section{Results and discussion}

Sorbent characterization

\section{FT-IR spectrometry}

FT-IR spectrometry was used to characterize the structure of the PMMA and methyl methacrylate 
/Na-Y- Zeolite composite (Fig. 1a, 1b), respectively. The FT-IR spectrum of PMMA shows a distinct absorption band from 1147.44 to $1270.86 \mathrm{~cm}^{-1}$, which can be attributed to the C-O$\mathrm{C}$ stretching vibration. The band at $1733.69 \mathrm{~cm}^{-1}$ shows the presence of the acrylate carbonyl group. The band at $1448.28 \mathrm{~cm}^{-1}$ can be attributed to the bending vibration of the $\mathrm{C}-\mathrm{H}$ bonds of the $-\mathrm{CH}_{3}$ group. The two bands at 2998.77 and $2952.48 \mathrm{~cm}^{-}$ ${ }_{1}$ can be assigned to the $\mathrm{C}-\mathrm{H}$ bond stretching vibrations of the $-\mathrm{CH}_{3}$ and $-\mathrm{CH}_{2-}$ groups, respectively. The FT-IR spectrum of methyl methacrylate /Na-Y- Zeolite composite shows a shift of the carbonyl band by about $100 \mathrm{~cm}^{-1}$ this behavior is similar to that suggested by Kabanov [29] and Diab et al [30] in polymerization of MMA in the presence of $\mathrm{ZnCl}_{2}, \mathrm{AlCl}_{2}$ and some transition metal chlorides, respectively.

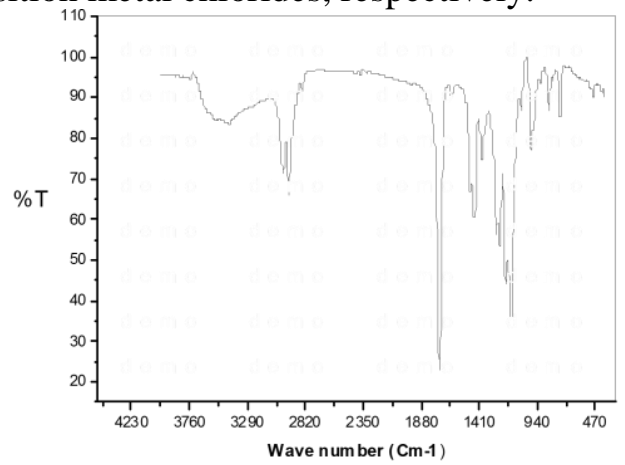

(a)

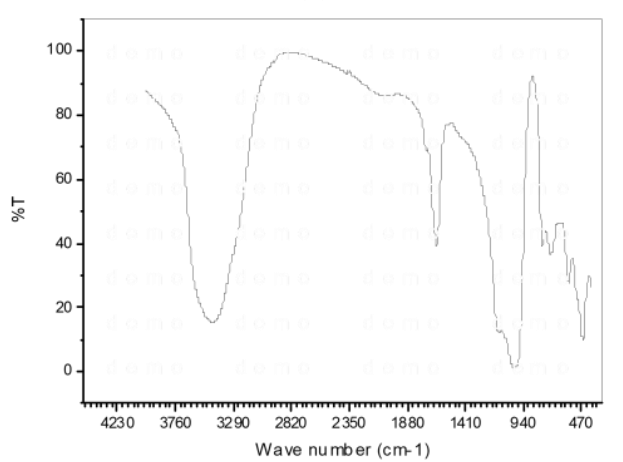

(b)

Figure 1: FT-IR analysis of (a) PMMA and (b) MMA/Na-Y-Zeolite composite

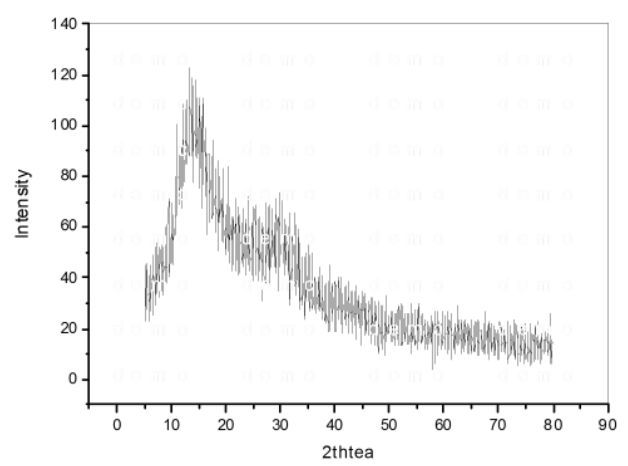

(a)

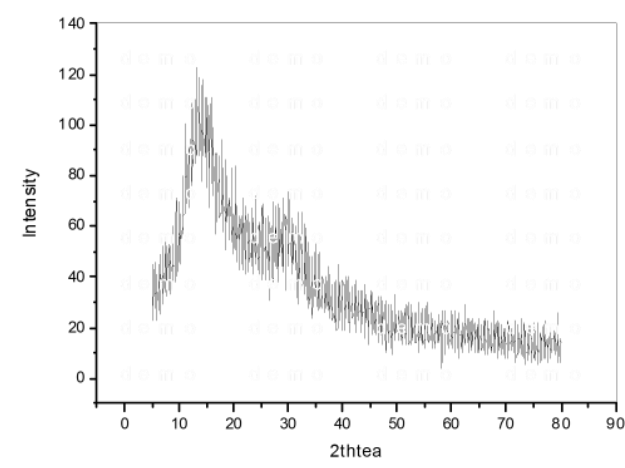

(b)

Figure 2: XRD analysis of (a) PMMA and (b) MMA / Na-Y-Zeolite composite

\section{X-ray of MMA/Na-Y-Zeolite composite}

The X-ray diffraction (XRD) patterns of PMMA/ homopolymer (Fig.2a) shows the amorphous phase. The X-ray diffraction (XRD) patterns of MMA/Na-Y-Zeolite composite presented in (Fig.2b) shows many diffraction peaks which confirm the polycrystalline phase. The average crystallite size $(\xi)$ and dislocation density $(\delta)$ can be calculated from the XRD according to the following equations [31, 32].

$$
\begin{aligned}
\xi & =\frac{K \lambda}{\beta_{1 / 2} \cos \theta} \\
\delta & =\frac{1}{\xi^{2}}
\end{aligned}
$$

Where $\lambda$ is wavelength of $\mathrm{X}$-ray radiation $(1.541874 \AA), \mathrm{K}$ is constant taken as 0.95 for organic compounds and $\beta_{1 / 2}$ is full width at half maximum of the reference diffraction peak measured in radians and $\theta$ is the angle of diffraction. The calculated values of $\xi$ are found $470.75,485.11,478.92$ and 492.515 .

\section{Sorption of methyl methacrylate / Na-Y-Zeolite composite}

\section{Effect of $p H$}

The $\mathrm{pH}$ of the aqueous solution is an important parameter affecting dye adsorption. The effect of $\mathrm{pH}$ on the adsorption of Sunfix Blue SF-RL dye on the methyl methacrylate / Na-Y-zeolite composite was investigated in the initial $\mathrm{pH}$ range of 2-8. For Sunfix Blue SF-RL dye (Fig. 3). The removal of the tested dye by methyl methacrylate / Na-Y-Zeolite composite at different $\mathrm{pH}$ values was studied at initial concentrations of $100 \mathrm{mg} / \mathrm{L}$ of the dye, $25^{\circ} \mathrm{C}$ and $10 \mathrm{~g} / \mathrm{L}$ adsorbent dosage. The $\mathrm{pH}$ value of the solution was an important 
controlling parameter in the adsorption process. methyl methacrylate / Na-Y-Zeolite composite has proved to be an effective adsorbent for the removal of the dye, which was achieved via adsorption from an aqueous solution at $\mathrm{pH} 2$ was achieved (Fig. 3). It shows that the adsorption capacity of tested dye onto methyl methacrylate / Na-Y-Zeolite composite increases significantly with decreasing $\mathrm{pH}$. The maximum removals for contact time $120 \mathrm{~min}$. were carried out at $\mathrm{pH} 2$.

As the $\mathrm{pH}$ of the adsorption system increases, the number of negatively charged sites increases and the number of positively charged sites decreases. A negatively charged surface site on the adsorbent does not favor the adsorption of dye anions, due to the electrostatic repulsion. Also, lower adsorption of tested dye at alkaline $\mathrm{pH}$ is due to the presence of excess hydroxyl ions competing with the dye anions for the adsorption sites [33].

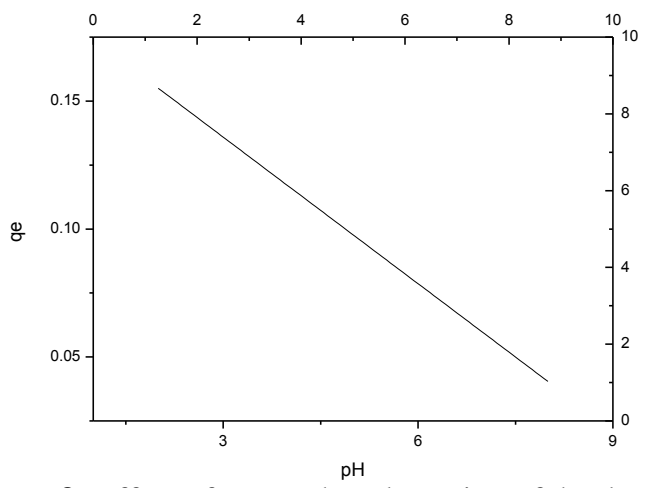

Figure 3: Effect of $\mathrm{pH}$ on the adsorption of the dye onto MMA/Na-Y-Z

\subsubsection{Kinetic studies}

The uptake kinetics of Sunfix Blue SF-RL dye using the MMA- Na-Y-Zeolite composite is shown in (Fig. 4). It can be observed that adsorption process for dye is rapid at initial stage and decreases gradually reaching equilibrium at Table 1: Kinetic parameters for Sunfix Blue SF-RL dye adsorption

\begin{tabular}{|c|c|c|c|c|c|c|c|c|c|}
\hline \multicolumn{5}{|c|}{ PFORE } & \multicolumn{5}{|c|}{ PSORE } \\
\hline \multirow{2}{*}{$\begin{array}{l}\mathrm{q}_{\mathrm{e}, \exp }\left(\mathrm{mg} \mathrm{g}^{-1}\right) \\
0.1697793\end{array}$} & $\mathrm{k}_{1}\left(\min ^{-1}\right)$ & \multicolumn{2}{|c|}{$\mathrm{q}_{\mathrm{e}, \text { calc }}\left(\mathrm{mg} \mathrm{g}^{-1}\right)$} & $\mathrm{R}^{2}$ & \multicolumn{2}{|c|}{$\mathrm{k}_{2}\left(\mathrm{~g} \mathrm{mg}^{-1} \min ^{-1}\right)$} & \multicolumn{2}{|c|}{$\mathrm{q}_{\mathrm{e}, \mathrm{calc}}\left(\mathrm{mg} \mathrm{g}^{-1}\right)$} & $\mathrm{R}^{2}$ \\
\hline & \begin{tabular}{l|l|} 
& -0.09964 \\
\end{tabular} & & 78151 & 0.82745 & 1.9562 & 33908 & 0.1 & 78651 & 0.99553 \\
\hline \multicolumn{10}{|c|}{ Table 2: Kinetics models and their linear forms } \\
\hline $\begin{array}{c}\text { Kinetic } \\
\text { model }\end{array}$ & \multicolumn{2}{|c|}{ Non-Linear form } & \multicolumn{3}{|c|}{ Linear form } & \multicolumn{2}{|c|}{ Plot } & Author & References \\
\hline $\begin{array}{l}\text { Pseudo-First } \\
\text { order }\end{array}$ & \multicolumn{2}{|c|}{$q_{t}=q_{e}\left[1-e^{-k_{1} t}\right]$} & \multicolumn{3}{|c|}{$\log \left(\mathrm{q}_{\mathrm{e}}-\mathrm{q}_{\mathrm{t}}\right)=\log \mathrm{q}_{\mathrm{e}}-\left(\frac{\mathrm{k}_{1}}{2.303}\right) \mathrm{t}$} & \multicolumn{2}{|c|}{$\log \left(\mathrm{q}_{\mathrm{e}}-\mathrm{q}_{\mathrm{t}}\right) v s . \mathrm{t}$} & $\begin{array}{l}\text { (Lagergren } \\
, 1898)\end{array}$ & {$[34]$} \\
\hline $\begin{array}{l}\text { Pseudo- } \\
\text { Second } \\
\text { order }\end{array}$ & $q_{t}=\frac{k_{2} t}{1+k_{2} q_{e} t}$ & & $\frac{\mathrm{t}}{\mathrm{q}_{\mathrm{t}}}=\frac{1}{\mathrm{k}_{2} \mathrm{q}}$ & $+\left(\frac{1}{q_{e}}\right) t$ & & $\left(\mathrm{t} / \mathrm{q}_{\mathrm{t}}\right) v s$. & & $\begin{array}{l}\text { (Ho and } \\
\text { McKay, } \\
\text { 1999) }\end{array}$ & {$[35]$} \\
\hline
\end{tabular}

$55 \mathrm{~min}$. This may be due to the fact that at initial stage there are large number of active sites available for removal of dye, and removal is difficult as time increases because of repulsion between solutes and solid.

Uptake kinetics of dye sorption on the sorbent was analyzed using two models: the so-called pseudo-first order rate equation (PFORE) [34] and pseudo-second order rate equations (PSORE) [35]. These models and their linear forms are reported in Table 1 where $\mathrm{k}_{1}$ is the pseudo first order rate constant $\left(\mathrm{min}^{-1}\right)$ of sorption and $\mathrm{q}_{\mathrm{e}}$ and $\mathrm{q}_{\mathrm{t}}\left(\mathrm{mg} \mathrm{g}^{-1}\right)$ are the amounts of dye sorbed at equilibrium and time $t$, respectively, $\mathrm{k}_{2}$ is the pseudo second order rate constant $\left(\mathrm{g} \mathrm{mg}^{-1} \mathrm{~min}^{-1}\right)$. The validity of each model is checked by the correlation coefficient associated to linear fit. The best models for describing the kinetic data can be selected if R2 is equal to or near 1 . Table 2 reports the parameters of the different models for the studied adsorbents. Systematically, the best correlation coefficients were found for the PSORE model; this is confirmed by the plot of experimental data according the linearized forms of these models: (Fig. 4a, 4b) for PFORE and PSORE, respectively, show a best fit of kinetic profiles by PSORE. In addition, the comparison of equilibrium adsorption capacities for the calculated values and the experimental values are only consistent for the PSORE model: the equilibrium sorption capacities are found close to 0.16978 , and PSORE modeling gave value of 0.17865 , closer from experimental value than PFORE 1.77815. However, the PSORE describes kinetic data through a global approach, and does not take into account the contribution of diffusion mechanisms in the control of the kinetics. Under these conditions, the kinetic parameters should be considered as apparent rate coefficients. 


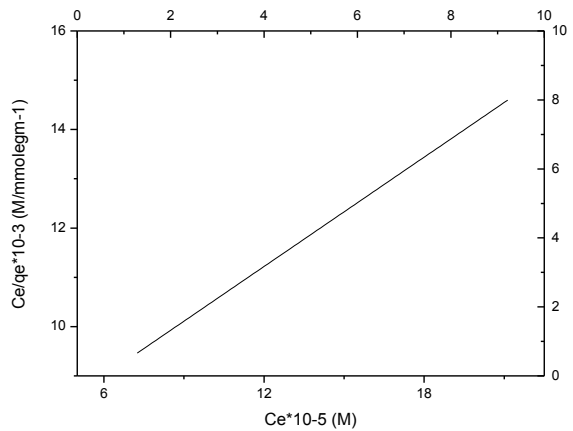

(a)

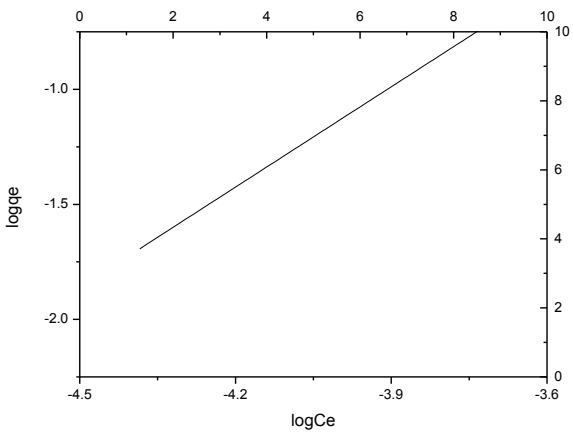

(b)

Figure 4: Dye uptake kinetics using MMA/Na-Y-Z sorbent

\section{Equilibrium sorption isotherm}

The adsorption isotherms reveal the specific relation between the concentration of adsorbate and the adsorption capacity of an adsorbent at a constant temperature. Adsorption isotherms provide some information on how an adsorption system proceeds, and indicate how molecules of adsorbate interact with adsorbent. Several isotherm models have been used to describe experimental data for sorption isotherms. The Langmuir [36] and Freundlich [37] models were used to explain the sorption of the dye on the MMA - Na-Y-Zeolite sorbent. These models and their linear forms are reported in Table 2 (see Supplementary Material Section), where $\mathrm{q}_{\mathrm{e}}$ the adsorbed amount of dye at equilibrium concentration $\left(\mathrm{mg} \mathrm{g}^{-1}\right), \mathrm{q}_{\mathrm{m}, \mathrm{L}}$ is the maximum sorption capacity (corresponding to the saturation of the monolayer, $\mathrm{mg} \mathrm{g}^{-1}$ ) and $\mathrm{Kl}$ is the Langmuir binding constant which is related to the energy of sorption $\left(\mathrm{L} \quad \mathrm{g}^{-1}\right), \mathrm{C}_{\mathrm{e}}$ is the equilibrium concentration of dye in solution $\left(\mathrm{mgL}^{-1}\right) . \mathrm{K}_{\mathrm{f}}(\mathrm{mg}$ $\left.\mathrm{g}^{-1}\right)\left(\mathrm{L} \mathrm{mg}^{-1}\right)^{1 / \mathrm{n}}$ and $\mathrm{n}$ are the Freundlich constants related to the sorption capacity and intensity, respectively.

Table 3: Parameters of the models for adsorption isotherms

\begin{tabular}{c|c|c|c|c|c|c}
\hline & \multicolumn{3}{|c|}{ Langmuir model } & \multicolumn{3}{|c}{ Freundlich model } \\
\hline $\begin{array}{c}\mathrm{q}_{\mathrm{m}, \exp } \\
\left(\mathrm{mg} \mathrm{g}^{-1}\right)\end{array}$ & $\begin{array}{c}\mathrm{q}_{\mathrm{m}, \mathrm{L}} \\
\left(\mathrm{mg} \mathrm{g}^{-1}\right)\end{array}$ & $\begin{array}{c}\mathrm{K}_{\mathrm{L}} \\
\left(\mathrm{L} \mathrm{g}^{-1}\right)\end{array}$ & $\mathrm{R}^{2}$ & $\mathrm{n}$ & $\begin{array}{c}\mathrm{K}_{\mathrm{F}} \\
\left(\mathrm{mg} \mathrm{g}^{-1}\right)\end{array}$ & $\mathrm{R}^{2}$ \\
\hline 0.13775 & 0.27878 & 0.0545 & 0.91 & 0.688217 & 4.6777 & 0.82 \\
\hline
\end{tabular}

The Langmuir isotherm models were found to be the most suitable models for describing the isotherm for the adsorption of the dye onto the MMA / Na-Y-Zeolite sorbent (Fig. 5a, 5b). Via comparison of the R2 values, the Langmuir isotherm resulted in very good fitting, with $\mathrm{R}_{2}$ value of $>0.90$. In addition, the $\mathrm{Q}_{\mathrm{m}}$ calculated from the Langmuir isotherm was close to the experimental $\mathrm{Q}_{\max }$.

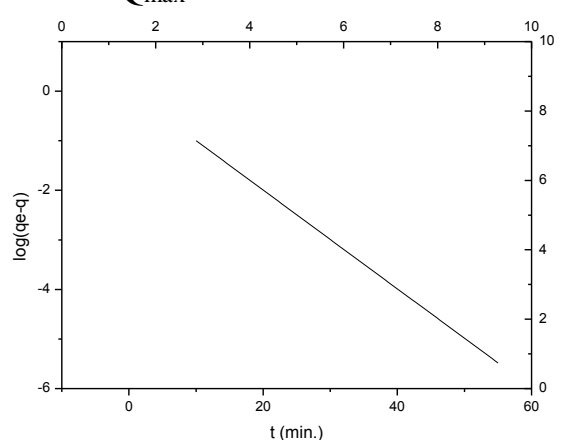

(a)

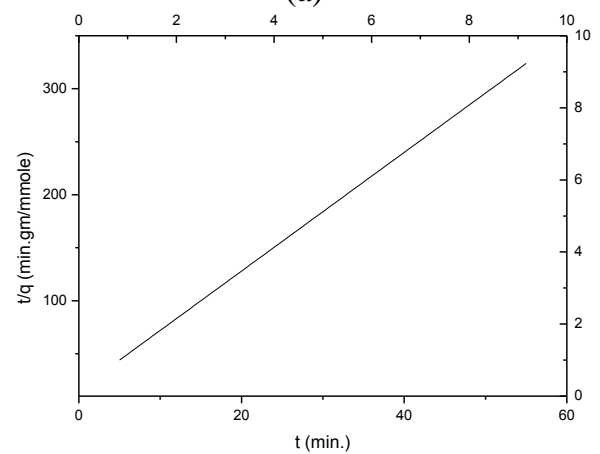

(b)

Figure 5: Dye sorption isotherms onto MMA/Na-Y-Z sorbent

Table 4: Sorption isotherms and their linear forms

\begin{tabular}{l|l|l|l|l|l}
\hline \multicolumn{1}{c}{ Isotherm } & Non-Linear form & Linear form & Plot & Author & References \\
\hline Langmuir & $q_{e}=\frac{q_{m, L} K_{L} C_{e}}{1+K_{L} C_{e}}$ & $\frac{\mathrm{C}_{\mathrm{e}}}{\mathrm{q}_{\mathrm{e}}}=\frac{\mathrm{C}_{\mathrm{e}}}{\mathrm{q}_{\mathrm{m}, \mathrm{L}}}+\frac{1}{K_{L} \mathrm{q}_{\mathrm{m}, \mathrm{L}}}$ & $\frac{\mathrm{C}_{\mathrm{e}}}{\mathrm{q}_{\mathrm{e}}}$ vs. $\mathrm{C}_{\mathrm{e}}$ & (Langmuir, 1918) & {$[36]$} \\
\hline Freundlich & $q_{e}=K_{F} C_{e}^{1 / n}$ & $\ln \mathrm{q}_{\mathrm{e}}=\ln \mathrm{K}_{\mathrm{f}}+\frac{1}{\mathrm{n}} \ln \mathrm{C}_{\mathrm{e}}$ & $\ln \mathrm{q}_{\mathrm{e}} v s . \ln \mathrm{C}_{\mathrm{e}}$ & (Freundlich, 1906) & [37] \\
\hline
\end{tabular}




\section{Influence of temperature}

It is important to investigate the effect of temperature on adsorption in a view of practical application. The adsorption experiments were carried out at six different temperatures including $25,30,40,50$ and $60{ }^{\circ} \mathrm{C}$. The adsorption capacity slightly increases with the increase in the temperature from 25 to $50{ }^{\circ} \mathrm{C}$. This behavior confirms that the adsorption process is endothermic. The adsorption equilibrium constant, $\mathrm{K}_{\mathrm{c}}$ was determined (Eq. 7) and used with the van't Hoff equation (Eq. 11) and conventional thermodynamic equation (Eq. 10) for evaluating the thermodynamic constants of the sorbents (i.e., the standard enthalpy change, $\Delta \mathrm{H}^{\circ}$, the standard free Gibbs energy, $\Delta \mathrm{G}^{\circ}$, and the standard entropy change, $\Delta S^{\circ}$ ).

$\mathrm{K}_{\mathrm{c}}=\frac{q_{e}}{C_{e}}$

Where $\mathrm{q}_{\mathrm{e}}$ and $\mathrm{C}_{\mathrm{e}}$ are equilibrium concentrations of metal ions on the adsorbent and in the solution, respectively.

$\Delta \mathrm{G}^{\mathrm{o}}=-\mathrm{RT} \ln \mathrm{K}_{\mathrm{c}}$

$\Delta \mathrm{G}^{\mathrm{o}}=\Delta \mathrm{H}^{\mathrm{o}}-\mathrm{T} \Delta \mathrm{S}^{\mathrm{o}}$ $\ln K_{\mathrm{C}}=\frac{-\Delta \mathrm{H}^{\circ}}{\mathrm{RT}}+\frac{\Delta \mathrm{S}^{\circ}}{\mathrm{R}}$

The values of standard enthalpy change $\left(\Delta \mathrm{H}^{\circ}\right)$ and standard entropy change $\left(\Delta S^{\circ}\right)$ for the adsorption process are determined from the slope and intercept for the plot of $\ln K_{c}$ versus 1/T (Fig. 6). The values of thermodynamic parameters are reported in Table 5. The positive values of $\Delta \mathrm{H}^{\circ}$ confirm the endothermic nature of sorption process and the negative values indicate the exothermic reaction. The positive values of $\Delta \mathrm{G}^{\circ}$ indicate that the sorption reaction is nonspontaneous and the negative values of $\Delta \mathrm{G}^{\circ}$ indicate that the sorption reaction is spontaneous.

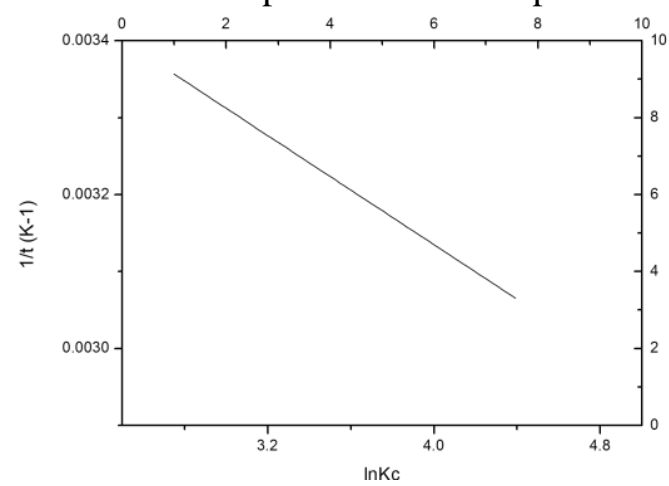

Figure 6: Effect of temperature on dye sorption using MMA/Na-Y-Z sorbent.

Therefore the van't Hoff equation becomes:

Table 5: Standard enthalpy, entropy and free energy changes for adsorption.

\begin{tabular}{|c|c|c|c|c|c|c|c|}
\hline \multirow{2}{*}{$\begin{array}{l}\Delta \mathrm{H}^{\mathrm{o}} \\
\left(\mathrm{kJ} \mathrm{mol}{ }^{-1}\right)\end{array}$} & \multirow{2}{*}{$\begin{array}{l}\Delta \mathrm{S}^{\mathrm{o}} \\
\left(\mathrm{J} \mathrm{mol}^{-1} \mathrm{~K}^{-1}\right)\end{array}$} & \multirow{2}{*}{$\mathrm{R}^{2}$} & \multicolumn{5}{|c|}{$\Delta \mathrm{G}^{\mathrm{o}}\left(\mathrm{kJ} \mathrm{mol}^{-1}\right)$} \\
\hline & & & $298 \mathrm{~K}$ & $303 \mathrm{~K}$ & $313 \mathrm{~K}$ & $323 \mathrm{~K}$ & $333 \mathrm{~K}$ \\
\hline-0.001473 & 0.03192576 & 0.87 & -0.0095 & -0.0097 & $\begin{array}{l}-0.0099 \\
\end{array}$ & -0.01 & -0.011 \\
\hline
\end{tabular}

\section{Effect of sorbent dose}

The adsorption of dye on the MMA-Na-Y-Zeolite composite was studied by changing the quantity of adsorbent range of $(0.05$ to 0.25$) \mathrm{g}, 50 \mathrm{~mL}$ with the dye concentration of $100 \mathrm{mg} \mathrm{L}^{-1}$ at $\pm 25^{\circ} \mathrm{C}$ and pH 2. The results in Fig. 7 show the dye adsorption capacity as a function of adsorbent amount. It has been found that the adsorption capacity decreases from 51 to $8 \mathrm{mg} / \mathrm{g}$ when the dose of composite increases from 0.05 to $0.25 \mathrm{~g}$. At low dose of adsorbent, all the sites are exposed entirely and the adsorption on the surface is saturated faster showing a higher adsorption capacity. An increase in the mass of adsorbent leads to a decrease in equilibrium adsorption capacity per unit weight of the adsorbent (qe) because there is excess adsorbent for the limited amount of dye in the solution. According to the result maximum removal efficiency is $84 \%$.

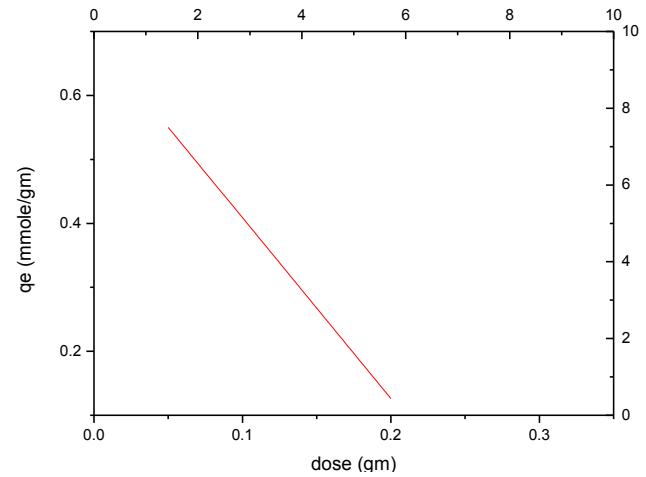

Figure 7: Effect of sorbent dose (SD) on dye sorption using MMA/Na-Y-Z sorbent.

\section{Regeneration}

Desorption of dye is generally operated by $\mathrm{pH}$ change. In most cases, desorption is performed under basic conditions. Regeneration of the composite was carried by contacting $20 \mathrm{~mL}$ of 0.1 
$\mathrm{N} \mathrm{NaOH}$ with composite for $60 \mathrm{~min}$. After regeneration the composite was again carefully washed with distilled water to become ready for the second run of uptake. The regeneration efficiency for each adsorption/desorption cycle was found to be $77 \%$.

\section{Determination of point of zero charge ( $p H p z c)$}

The pHpzc gives very significant information about the type of surface active centers. The $\mathrm{pH}$ of MMA/Na-Y-Zeolite composite was found to be 7.5. This shows that below this $\mathrm{pH}$, the composite acquires a positive charge due to protonation of functional groups and above this $\mathrm{pH}$, negative charge exists on the surface of composite.

\section{Conclusion}

The present study clearly demonstrated that (MMA/Na-Y-Zeolite) composite is an effective adsorbent for the removal of the dye from aqueous solution and polluted water. The prepared sorbents are characterized by efficient and selective sorption towards the dye from aqueous medium at approximately $\mathrm{pH} 2$. Adsorption parameters for Langmuir and Freundlich isotherms were determined and the equilibrium data fit well with Langmuir equation for the adsorption of the dye. The kinetic data tends to fit very well in the pseudo-second-order kinetic model with high correlation coefficients. The thermodynamics of the adsorption indicated spontaneous and endothermic reaction.

Desorption studies were conducted and the results showed that (MMA/Na-Y-Zeolite) composite can be used in adsorption of the dye several times by regeneration process using $0.1 \mathrm{~N}$ sodium hydroxide solution. Finally, taking into consideration of the results above, it can be concluded that the (MMA/Na-Y-Zeolite) composite is a suitable adsorbent for the dye from wastewaters in terms of high adsorption capacity, natural and abundant availability and low cost.

\section{References}

T. Kalburc, A. Tabak, N. Ozturk, N. Tuzmen, S. Akgol, B. Caglar, A. Denizli, Adsorption of lysozyme from aqueous solutions by a novel bentonite-tyrptophane (Bent-Trp) microcomposite affinity sorbent, J. Mol. Struct. 1083 (2015) 156.

L. S. Oliveira,A. S. Franca,T. M. AlvesSônia, D. F. Rocha, Evaluation of untreated coffee husks as potential biosorbents for treatment of dye contaminated waters, J. Hazard. Mater. 155 (2008) 507.

R.P.F. Melo, E.L. Barros Neto, M.C.P.A. Moura, T.N. Castro Dantas, A.A. Dantas Neto, H.N.M. Oliveira, Removal of Reactive Blue 19 using nonionic surfactant in cloud point extraction, Sep. Purif. Technol. 138 (2014) 71.

T. T. Ma, P. R. Chang, P. W. Zheng, F. Zhao, X. F. Ma, Fabrication of ultra-light graphene-based gels and their adsorption of methylene blue, Chem. Eng. J. 240 (2014) 595.

M. R. Patil and V. S. Shrivastava, Adsorption removal of carcinogenic acid violet19 dye from aqueous solution by polyaniline- $\mathrm{Fe}_{2} \mathrm{O}_{3}$ magnetic nanocomposite, J. Mater. Environ. Sci. 6(1) (2015) 11.

M. Ghaedi, H. Khajehsharifi, A. H. Yadkuri, M. Roosta, A. Asghari, Oxidized multiwalled carbon nanotubes as efficient adsorbent for bromothymol blue, Toxicol. Environ. Chem. 94 (2012) 873.

T.A. Ammar, K.Y. Abid, A.A. El-Bindary, A.Z. ElSonbati, Chlorine dioxide bulk decay prediction in desalinated drinking water, Desalination 352 (2014) 45 .

A. A. El-Bindary, M. A. Hussien, M. A. Diab, A. M. Eessa, Adsorption of Acid Yellow 99 by polyacrylonitrile/activated carbon composite: Kinetics, thermodynamics and isotherm studies, J. Mol. Liq. 197 (2014) 236

A. A. El-Bindary, M. A. Diab, M. A. Hussien, A. Z. ElSonbati, A. M. Eessa, Adsorption of Acid Red 57 from aqueous solution onto polyacrylonitrile/activated carbon composite, Spectrochim. Acta A 124 (2014) 70.

M. Ghaedi, A. Ansari, M. H. Habibi, A. R. Asghari, Removal of malachite green from aqueous solution by zinc oxide nanoparticle loaded on activated carbon: Kinetics and isotherm study, J. Ind. Eng. Chem. 20 (2014) 17.

M.R. Fathi, A. Asfaram, A. Farhangi, Removal of Direct Red 23 from aqueous solution using corn stalks: Isotherms, kinetics and thermodynamic studies, Spectrochim. Acta A 135 (2015) 364.

M. S. Sajab, C. H. Chia, S. Zakaria, P. S. Khiew, Cationic and anionic modifications of oil palm empty fruit bunch fibers for the removal of dyes from aqueous solutions, Bioresour. Technol. 128 (2013) 571.

S. Wang, Y. Boyjoo, A. Choueib, Z.H. Zhu, Removal of dyes from aqueous solution using fly ash and red mud, Water Res. 39 (2005) 129.

P.C.C Faria, J.J.M Órfão, M.F.R Pereira, Adsorption of anionic and cationic dyes on activated carbons with different surface chemistries, Water Res. 38 (2014) 2043.

A. A. El-Bindary, A. Z. El-Sonbati, A. A. Al-Sarawy, K. S. Mohamed, M. A. Farid, Adsorption and 
thermodynamic studies of hazardous azocoumarin dye from an aqueous solution onto low cost rice straw-based carbons, J. Mol. Liq. 199 (2014) 71.

M. Roosta, M. Ghaedi, N. Shokri, A. Daneshfar, R. Sahraei, A. Asghari., Removal of malachite green by gold nanoparticles loaded on activated carbon: experimental design, Spectrochim. Acta A 118 (2014) 55

S. S. Madaeni, Z. Jamali, N. Islami, Highly efficient and selective transport of methylene blue through a bulk liquid membrane containing Cyanex 301 as carrier, Sep. Purif. Technol., 81(2011), 116.

Serpone N, Horikoshi S, Emeline AV (2010) Microwaves in advanced oxidation processes for environmental applications. A brief review. J. Coll. Interf. Sci. 430 (2014) 166.

G.Z. Kyzas, E.A. Deliyanni, N.K. Lazaridis, Magnetic modification of microporous carbon for dye adsorption, J. Coll. Interf. Sci. 430 (2014) 166.

M. Asgher, H. N. Bhatti, Evaluation of thermodynamics and effect of chemical treatments on sorption potential of citrus waste biomass for removal of anionic dyes from aqueous solutions, Ecol. Eng. 38 (2012) 79.

S. Yang, M. Gao, Z. Luo, Adsorption of 2-Naphthol on the organo-montmorillonites modified by Gemini surfactants with different spacers, Chem. Eng. J. 256 (2014) 39.

A. M. Alsabagh, M. Fathy and R. E. Morsi, Preparation and characterization of chitosan/silver nanoparticle/copper nano particle/carbon nanotube multifunctional nano-composite for water treatment: heavy metals removal; kinetics, isotherms and competitive studies, RSC Adv. 5 (2015) 55774.

K. H. Kima, A. A. Keller, J. K. Yang, Removal of heavy metals from aqueous solution using a novel composite of recycled materials, Colloid. Surface. A. 425 (2013) 6.

D. Karadag, E. Akgul, S. Tok, F. Erturk, M. A. Kaya, M. Turan, Basic and Reactive dye removal using natural and modified zeolites, J. Chem. Eng. Data, 52 (2007) 2436.

B. Armagan, O. Ozdemir, M. Turan, M. S. Celik, The removal of reactive azo dyes by natural and modified zeolites, J. Chem. Technol. Biotechnol., 78 (2003) 725 .
G. Amin, D. Dordević, S. Konstantinovic, I. Jordanov, The removal of the textile basic dye from the water solution by using natural zeolite, Advanced technologies, 6(2) (2017) 67.

A. U. Metin, Synthesis, Physical properties, and application of aminated poly(glycidyl methacrylate)/zeolite composite, polym. Composites, 37(8) (2015) 2313.

M. Mullet, P. Fievet, A. Szymczyk, A. Foissy, J. C. Reggiani, J. Pagetti, A simple and accurate determination of the point of zero charge of ceramic membranes, Desalin,, 121 (1999) 41.

V. A. Kabanov, IUPAC International Sympersium on Macromolecular Chemistry, Budapest, p 435-462 (1969).

M. A.Diab, A. Z.El-sonbati, A. S.Hilali, H. M. Killa , M. M.Ghoneim,Polymer complexes X. Polymerization of methyl methacrylate in presence of some transition metal salts, Eur. Polym. J., 26 (1990) 1.

M. M. Ghoneim, A. Z. El-Sonbati, A. A. El-Bindary, M. A. Diab, L. S. Serag, Polymer complexes. LX. Supramolecular coordination and structures of $\mathrm{N}$ (4-(acrylamido)-2-hydroxybenzoic acid) polymer complexes, Spectrochim. Acta. A. 140 (2015) 111.

A. A. El-Bindary, A. Z. El-Sonbati, M. A. Diab, S. M. Morgan, Geometrical structure, potentiometric and thermodynamic studies of rhodanineazodye and its metal complexes, J. Mol. Liq., 201 (2015) 36.

D. A. Fungaro, S. I. Borrely, T. E.M. Carvalho, Surfactant modified zeolite from cyclone ash as adsorbent for removal of reactive orange 16 from aqueous solution, Amer. J. Envir. Prot., 1 (2013) 1.

S. Lagergren, About the theory of so-called adsorption of soluble substances, Kungliga Swenska Vet., 24 (1898) 1 .

Y.S. Ho, G. McKay, Pseudo-second order model for sorption processes, Process Biochem., 34 (1999) 451.

I. Langmuir, The adsorption of gases on plane surfaces of glass, mica and platinum, J. Amer. Chem. Soc., 40 (1918) 1361.

H. M. F. Freundlich, Uber die adsorption in lasungen, Z. Phys. Chem., 57 (1906) 385. 


\section{الملخص العربي}

عنوان البحث: إزالة صبغة صنفكس الزرقاء من محاليلها المائية باستخدام مركب بوليمرات الميثيل ميثأكريلات انزئ الزيوليت

محمود سالم إبراهيم'، عادل زكي السنباطي'، مصطفي أمين دياب'، تامر يس السعيد'

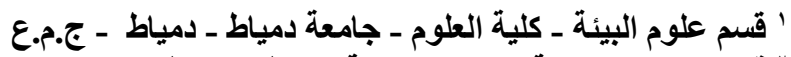

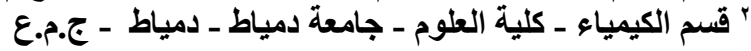

يتضمن البحث دراسة إمتزاز صبغة صنفكس الزرقاء من محاليلها المائية باستخدام مركب بوليمرات الميثيل وائيل

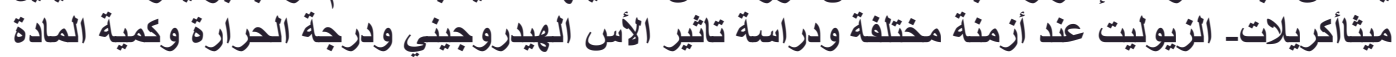

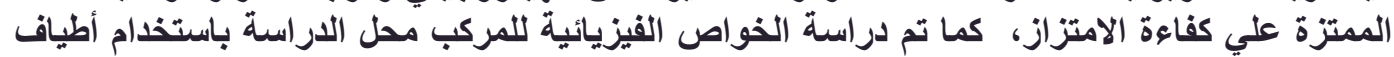

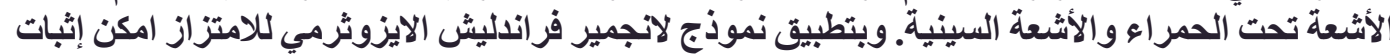

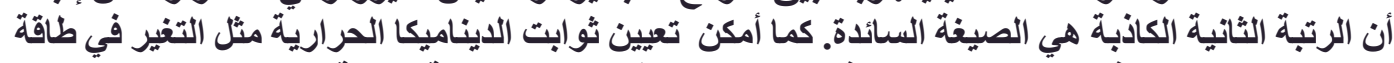

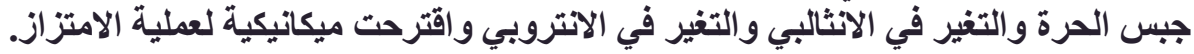

